\title{
Neurotrophin receptors expression and JNK pathway activation in human astrocytomas
}

\author{
Martha Assimakopoulou*1, Maria Kondyli², George Gatzounis², \\ Theodore Maraziotis ${ }^{1}$ and John Varakis ${ }^{1}$
}

\begin{abstract}
Address: ${ }^{1}$ Department of Anatomy, School of Medicine, University of Patras, 26500 Patras, Greece and ${ }^{2}$ Department of Neurosurgery, School of Medicine, University of Patras, 26500 Patras, Greece

Email: Martha Assimakopoulou* - massim@med.upatras.gr; Maria Kondyli - mkondyl@upatras.gr; George Gatzounis - g_gatzounis@web.de; Theodore Maraziotis - neurosur@med.upatras.gr; John Varakis - gvar@med.upatras.gr

* Corresponding author
\end{abstract}

Published: 3I October 2007

BMC Cancer 2007, 7:202 doi:10.1 186/147/-2407-7-202
Received: 22 December 2006

Accepted: 31 October 2007

This article is available from: http://www.biomedcentral.com/I47/-2407/7/202

(c) 2007 Assimakopoulou et al; licensee BioMed Central Ltd.

This is an Open Access article distributed under the terms of the Creative Commons Attribution License (http://creativecommons.org/licenses/by/2.0), which permits unrestricted use, distribution, and reproduction in any medium, provided the original work is properly cited.

\begin{abstract}
Background: Neurotrophins are growth factors that regulate cell growth, differentiation and apoptosis in the nervous system. Their diverse actions are mediated through two different transmembrane - receptor signaling systems: Trk receptor tyrosine kinases (TrkA, TrkB, TrkC) and p75NTR neurotrophin receptor. Trk receptors promote cell survival and differentiation while p75NTR induces, in most cases, the activity of JNK-p53-Bax apoptosis pathway or suppresses intracellular survival signaling cascades. Robust Trk activation blocks p75NTR -induced apoptosis by suppressing the JNKp53-Bax pathway. The aim of this exploratory study was to investigate the expression levels of neurotrophin receptors, Trks and p75NTR, and the activation of JNK pathway in human astrocytomas and in adjacent non-neoplastic brain tissue.

Methods: Formalin-fixed paraffin-embedded serial sections from 33 supratentorial astrocytomas ( 5 diffuse fibrillary astrocytomas, WHO grade II; 6 anaplastic astrocytomas, WHO grade III; 22 glioblastomas multiforme, WHO grade IV) were immunostained following microwave pretreatment. Polyclonal antibodies against TrkA, TrkB, TrkC and monoclonal antibodies against p75NTR and phosphorylated forms of JNK (pJNK) and c-Jun (pc-Jun) were used. The labeling index (LI), defined as the percentage of positive (labeled) cells out of the total number of tumor cells counted, was determined.

Results: Moderate to strong, granular cytoplasmic immunoreactivity for TrkA, TrkB and TrkC receptors was detected in greater than or equal to $10 \%$ of tumor cells in the majority of tumors independently of grade; on the contrary, p75NTR receptor expression was found in a small percentage of tumor cells $(\sim \mid \%)$ in some tumors. The endothelium of tumor capillaries showed conspicuous immunoreactivity for TrkB receptor. Trk immunoreactivity seemed to be localized in some neurons and astrocytes in non-neoplastic tissue. Phosphorylated forms of JNK (pJNK) and c-Jun (pc-Jun) were significantly co-expressed in a tumor grade-dependent manner $(p<0.05)$. Interestingly, a statistically significant $(p<0.05)$ reverse relationship between Trk receptors Lls and pc-Jun/pJNK Lls was noted in some glioblastomas multiforme.

Conclusion: In the context of astrocytomas, Trk receptors (TrkA, TrkB, TrkC) expression may promote tumor growth independently of grade. Furthermore, activation of JNK pathway may contribute to progression towards malignancy. Considering the fact that regional tumor heterogeneity may be a limiting factor for immunohistochemical studies, the significance of the reverse relationship between Trk receptors and pc-Jun/pJNK Lls with respect to biological behavior of human astrocytomas requires further evaluation.
\end{abstract}




\section{Background}

Neurotrophins, a family of highly conserved polypeptide growth factors [nerve growth factor (NGF), brain derived neurotrophic factor (BDNF), neurotrophin-3 (NT-3), and neurotrophin 4/5 (NT-4/5)] play a crucial role in function of developing and adult vertebrate nervous system [1-3]. These growth factors mediate their actions through activation of two different transmembrane - receptor signaling systems: the Trk receptor tyrosine kinases (TrkA, TrkB, TrkC) and the $\mathrm{p} 75^{\mathrm{NTR}}$ neurotrophin receptor, a member of tumor necrosis factor (TNF) receptor superfamily $[3,4]$.

Trk receptors promote cell survival via several intracellular signaling cascades e.g. Ras/PI-3k/Akt pathway [1-4]. In most cases, p75NTR functions as a ligand-stimulated apoptotic receptor inducing the activity of the JNK-p53-Bax pathway or suppressing Ras/PI-3k/Akt activation. Robust Trk activation blocks p75 $5^{\mathrm{NTR}}$-induced apoptosis by suppressing the JNK-p53-Bax pathway $[3,4]$. Recent data reveal that precursor forms of some neurotrophins (proneurotrophins) have the capacity to bind with high affinity to $\mathrm{p} 75^{\mathrm{NTR}}$ but not to Trk receptors suggesting that proneurotrophins can elicit apoptosis via p $75^{\mathrm{NTR}}$ even in cells expressing survival-promoting Trk receptors [5-8].

The major downstream target of JNK [c-Jun N-terminal kinases (JNKs)/Stress-activated protein kinases (SAPKs) MAP kinases] is the c-Jun transcription factor which is phosphorylated at serine residues 63 and 73 [9]. The axis JNK/c-Jun is considered to play a crucial role in signal transduction in the mammalian brain [10] while constitutive activation of JNK pathway has been linked with glial tumor development and progression [11].

Gliomas of astrocytic origin are the most common primary brain tumors of adults [12]. Astrocytomas accumulate genetic lesions affecting signal transduction pathways that control cell survival and differentiation [13]. These pathways are known to be implicated in the signaling cascades of neurotrophins via their receptors Trks and p75 NTR [14]. The aberrant expression or mutations of the genes encoding these receptors has been associated with gliomas [15-18] as well as medulloblastomas and neuroblastomas [15,19-21]. Recently, tyrosine kinase inhibitors (TKIs) have been designed to selectively inhibit the growth of gliomas [22,23].

The aim of this study was to investigate immunohistochemicaly the expression levels of neurotrophin receptors TrkA, TrkB, TrkC, p75 NTR and phosphorylated forms of JNK (pJNK) and c-Jun (pc-Jun) in serial sections of human astrocytomas of different grade of malignancy.

\section{Methods \\ Tissue samples}

Astrocytic gliomas $(n=33)$ were obtained from patients who had undergone surgery at Department of Neurosurgery of the Patras University Hospital (Patras, Greece) from 1991 to 1996. The formalin-fixed, paraffin-embedded archival tissue blocks were retrieved, and the matching hematoxylin and eosin ( $\mathrm{H} \& \mathrm{E})$ - stained slides were reviewed and screened for representative tumor regions by a neuropathologist. Tumors were evaluated by routine methods for histopathology including immunohistochemical staining for glial fibrillary acidic protein (GFAP) and Ki-67 index as proliferation marker and graded according to the diagnostic criteria of the WHO classification system [12]. The tumor characteristics and clinical features of the 33 patients are illustrated in Table 1.

\section{Antibodies}

Anti-pan-Trk (B-3) (dilution, 1:500), a mouse monoclonal antibody that reacts with a highly conserved carboxy terminus of TrkA gp140 and is reactive with TrkA, TrkB, and TrkC receptors, anti-TrkA (763), a rabbit polyclonal antibody against a carboxy terminal epitope of human TrkA (amino acids 763-777) (dilution, 1:100), anti-TrkB (794) (dilution, 1:100), and anti-TrkC (798) (dilution, 1:100), rabbit polyclonal antibodies against carboxy terminal peptides (794-808 and 798-812 residues respectively) of gp145TrkB or gp145TrkC proteins were purchased from Santa Cruz Biotechnology (Santa Cruz, CA). Antibodies recognize the full-length isoforms of Trk receptors and the catalytic intracellular tyrosine kinase domain. According to the manufacturer, antibodies do not cross react with each other. Anti-phospho-c-Jun (KM-1) (dilution, 1:100), a mouse monoclonal antibody which detects c-Jun only when it is phosphorylated on Ser63 and anti-phospho-JNK (G-7) (dilution, 1:100), a mouse monoclonal antibody directed against the carboxy terminus of JNK1 phosphorylated on $\mathrm{Thr}^{183}$ and $\mathrm{Tyr}^{185}$ (identical to corresponding JNK2 sequence), were also purchased from Santa Cruz Biotechnology (Santa Cruz, CA). A mouse monoclonal anti-nerve growth factor receptor (p75 ${ }^{\mathrm{NGFR}}$ ) antibody (dilution, 1:500) directed against amino acids $1-160$ of extracellular domain of $\mathrm{p} 75^{\mathrm{NTR}}$ was purchased from Lab Vision Corporation (Fermont, CA).

\section{Immunohistochemistry}

Immunohistochemical studies were performed on $4 \mu \mathrm{m}$ thick serial sections. A standard biotin-streptavidin peroxidase procedure (StrAvigen MultiLink, Super Sensitive Immunodetection System B-SA; Biogenex, San Ramon, CA) for detection of pan-Trk, p75 ${ }^{\text {NTR, }}$ pc-Jun and pJNK and an anti-mouse/rabbit poly HRP IHC Detection System (Chemicon International, Temecula, CA) for detection of TrkA, TrkB and TrkC were used according to manufacturers' specifications. In brief, antigen retrieval 
Table I: Trk receptors, pc-Jun and pJNK expression in human astrocytomas of different grade of malignancy.

\begin{tabular}{|c|c|c|c|c|c|c|c|c|c|c|}
\hline Case & Sex & Age & Histology/Grading & Prior treatment & pc-Jun & pJNK & panTrk & TrkA & TrkB & TrkC \\
\hline 1 & $\mathrm{~F}$ & 32 & Diffuse fibrillary astrocytoma/ll & No & 0 & ND & 70 & ND & 0 & 0 \\
\hline 2 & M & 56 & Diffuse fibrillary astrocytoma/ll & No & 2 & 2 & 50 & ND & 30 & 60 \\
\hline 3 & $\mathrm{~F}$ & 38 & Diffuse fibrillary astrocytoma/ll & No & 0 & 0 & 0 & 0 & 0 & 0 \\
\hline 4 & M & 24 & Diffuse fibrillary astrocytoma/ll & No & 10 & 10 & 10 & 10 & 5 & 5 \\
\hline 5 & M & 11 & Diffuse fibrillary astrocytoma/ll & No & 2 & 2 & 70 & 50 & ND & ND \\
\hline 6 & $\mathrm{~F}$ & 15 & Anaplastic astrocytoma/III & No & 0 & 0 & 2 & 1 & 5 & 0 \\
\hline 7 & $M$ & 62 & Anaplastic astrocytoma/III & No & 60 & 40 & ND & 50 & 60 & 40 \\
\hline 8 & M & 56 & Anaplastic astrocytoma/III & No & 0 & 0 & 20 & 10 & 1 & ND \\
\hline 9 & M & 46 & Anaplastic astrocytoma/III & No & I & 0 & 70 & 60 & 5 & 5 \\
\hline 10 & M & 30 & Anaplastic astrocytoma/III & Yes & 2 & ND & 5 & ND & ND & ND \\
\hline 11 & M & 35 & Anaplastic astrocytoma/III & No & 0 & 0 & 5 & 2 & 1 & 0 \\
\hline 12 & $\mathrm{~F}$ & 40 & Glioblastoma multiforme/IV & Yes & 0 & 0 & 0 & 0 & ND & ND \\
\hline 13 & M & 19 & Glioblastoma multiforme/IV & No & 10 & 10 & 30 & 60 & 30 & 0 \\
\hline 14 & M & 65 & Glioblastoma multiforme/IV & No & 90 & 90 & 20 & ND & 30 & ND \\
\hline 15 & $\mathrm{~F}$ & 57 & Glioblastoma multiforme/IV & No & 50 & 50 & 10 & ND & ND & ND \\
\hline 16 & $\mathrm{~F}$ & 53 & Glioblastoma multiforme/IV & Yes & 70 & 0 & 10 & ND & ND & 0 \\
\hline 17 & M & 67 & Glioblastoma multiforme/IV & No & 70 & 0 & 1 & 1 & 0 & 0 \\
\hline 18 & $\mathrm{~F}$ & 60 & Glioblastoma multiforme/IV & Yes & 10 & 10 & 50 & ND & ND & 50 \\
\hline 19 & M & 56 & Glioblastoma multiforme/IV & No & 70 & 90 & 80 & ND & 80 & 80 \\
\hline 20 & $\mathrm{~F}$ & 44 & Glioblastoma multiforme/IV & No & 0 & 90 & ND & 30 & I & 10 \\
\hline 21 & M & 67 & Glioblastoma multiforme/IV & No & 80 & 80 & 10 & 20 & 10 & 5 \\
\hline 22 & M & 60 & Glioblastoma multiforme/IV & No & 20 & 80 & 90 & ND & 60 & 75 \\
\hline 23 & $\mathrm{~F}$ & 59 & Glioblastoma multiforme/IV & No & 70 & 70 & 80 & ND & 20 & 20 \\
\hline 24 & M & 25 & Glioblastoma multiforme/IV & Yes & 5 & 0 & 40 & ND & 10 & 10 \\
\hline 25 & $\mathrm{~F}$ & 66 & Glioblastoma multiforme/IV & No & 90 & 40 & 60 & 60 & 30 & 10 \\
\hline 26 & M & 61 & Glioblastoma multiforme/IV & No & 25 & 10 & 90 & ND & 20 & 20 \\
\hline 27 & $\mathrm{~F}$ & 67 & Glioblastoma multiforme/IV & No & 60 & 10 & 90 & ND & 60 & 5 \\
\hline 28 & M & 42 & Glioblastoma multiforme/IV & No & 0 & 0 & 70 & 70 & ND & ND \\
\hline 29 & $M$ & 47 & Glioblastoma multiforme/IV & Yes & 30 & 0 & 50 & 50 & ND & ND \\
\hline 30 & $\mathrm{~F}$ & 65 & Glioblastoma multiforme/IV & No & 50 & 70 & 90 & ND & 70 & 2 \\
\hline 31 & M & 53 & Glioblastoma multiforme/IV & No & 70 & 60 & 30 & ND & ND & ND \\
\hline 32 & $\mathrm{~F}$ & 55 & Glioblastoma multiforme/IV & No & 60 & 40 & 30 & ND & 50 & 30 \\
\hline 33 & M & 77 & Glioblastoma multiforme/IV & No & I & 0 & 30 & ND & 0 & 0 \\
\hline
\end{tabular}

ND: Not detected due to lack of serial sections.

was performed by placing the unstained slides in 0.01 $\mathrm{mM}$ citrate buffer (PH 6.0) and treating them in a microwave oven for $10 \mathrm{~min}$. Overnight incubation at $4^{\circ} \mathrm{C}$ was performed for anti -pan-Trk, -p75 NTR, -pc-Jun and -pJNK primary antibodies and 1 hour at room temperature incubation was performed for anti-TrkA, -TrkB and -TrkC primary antibodies. Antigen-antibody reaction was visualized routinely using the peroxidase enhancer as a chromogen. Mayer's hematoxylin nuclear staining was used as a counter stain. Negative controls included unrelated primary antibodies. As positive controls, specimens of inflammatory intestine known to express Trks and p75 ${ }^{\text {NTR }}$ [24] and glioblastoma specimens known to express pc-Jun and pJNK [11] were used.

\section{Analysis of staining and statistical methods}

The results of immunohistochemical staining were evaluated independently by two observers. Using a final magnification of $400 \times$ (objective $\times$ eyepiece), ten non- overlapping fields were chosen at random and a total of 100 tumor cells were counted manually in every field with the aid of an ocular grid. To assess the fraction of immunolabeled cells in each case and each antibody, the labeling index (LI), defined as the percentage of positive (labeled) cells out of the total number of tumor cells counted, was determined. Labeled cells in tumor blood vessels/microvascular proliferation were excluded from the cell counts.

Nonparametric methods were used for the statistical analysis of the results. Spearman correlation was used to assess significance of relationships between different LIs and between age and LIs. Spearman correlation was also used to assess significance of relationships between LIs and grade. Wilcoxon rank test was used to compare LIs between male and female. P values $<0.05$ were considered significant. Statistical analyses were carried out using the SPSS package (version 12.0). 


\section{Results}

\section{Trk expression in astrocytomas}

Moderate to strong Trk immunoreactivity was found in the majority of astrocytomas included in this study. Trk immunoreactivity was cytoplasmic with granular appearance (Figures 1,2). The majority of the tumors exhibited areas with focally immunoreactive tumor cells, corresponding to $1-90 \%$ of the cell population while other areas were entirely immunonegative. The rest of the tumors displayed scattered immunoreactive tumor cells.

In diffuse fibrillary astrocytomas (WHO; grade II) reactive astrocytes showed strong immunoreactivity for all Trk receptors. Regarding grade IV tumors (glioblastomas multiforme), Trk-positively stained cells had a tendency to aggregate around tumor blood vessels or in the vicinity bordering tumor necrosis. Elongated, bipolar cells as well as giant cells (Figure 2) were intensely stained for all Trk receptors. In the majority of tumors, in immunopositive areas, the endothelium of tumor capillaries as well as florid angioproliferative changes and/or proliferations of smooth muscle cells showed conspicuous immunoreactivity for TrkB receptor. In the apparently "normal tissue" of peritumoral region found in some cases the Trk-immunoreactivity localized in some neurons and astrocytes. Blood capillaries were non reactive.

There was no statistically significant correlation between Trk expression and histological grade (Spearman correlation of grade with panTrk $=0.22, \mathrm{p}=0.22$, Spearman correlation of grade with $\operatorname{TrkA}=0.27, \mathrm{p}=0.30$, Spearman correlation of grade with $\operatorname{TrkB}=0.40, \mathrm{p}=0.05$, Spearman correlation of grade with TrkC $=0.21, \mathrm{p}=0.31)$. Trk expression was not significantly correlated with age
(Spearman correlation of age with panTrk $=0.27, \mathrm{p}=$ 0.13 , Spearman correlation of age with $\operatorname{TrkA}=0.11, \mathrm{p}=$ 0.66 , Spearman correlation of age with $\operatorname{TrkB}=0.25, \mathrm{p}=$ 0.24 , Spearman correlation of age with $\operatorname{TrkC}=0.23, \mathrm{p}=$ $0.27)$. Furthermore, Trk expression was not different by gender (Wilcoxon test: $\mathrm{p}=0.40$ for panTrk, $\mathrm{p}=0.27$ for $\operatorname{Trk} A, \mathrm{p}=0.52$ for TrkB, $\mathrm{p}=0.38$ for TrkC).

\section{p75NTR expression in astrocytomas}

p75 NTR immunoreactivity was confined to cytoplasm of a small number $(\sim 1 \%)$ of scattered or small clusters of tumor cells in a few tumors. Normal tissue was totally p75 ${ }^{\mathrm{NTR}}$-negative.

\section{Relationship between Trk and pc-Jun/pJNK expression}

Trk receptors, pc-Jun and pJNK expression was analyzed by examining adjacent (serial) sections of each specimen. Only the nuclear immunoreactivity was evaluated for both pc-Jun and pJNK proteins. There was a statistically significant association between pc-Jun and pJNK expression (Spearman correlation $=0.57, \mathrm{p}=0.001$ ). There was also a statistically significant positive correlation between pc-Jun/pJNK expression and grade of malignancy (Spearman correlation of $\mathrm{pc}$-Jun with grade $=0.52, \mathrm{p}=0.002$, Spearman correlation of $\mathrm{pJNK}$ with grade $=0.36, \mathrm{p}=$ $0.04)$. pc-Jun/pJNK expression was significantly correlated with age (Spearman correlation of age with pc-Jun $=0.60$, $\mathrm{p}=0.000$, Spearman correlation of age with $\mathrm{pJNK}=0.38$, $\mathrm{p}=0.03)$. pc-Jun/pJNK expression was not different by gender (Wilcoxon test: $p=0.89$ for $p c-J u n, p=0.83$ for pJNK). Normal tissue was pc-Jun and pJNK imunonegative. Regarding co-expression of Trk receptors and pc-Jun/ pJNK in the same tumor cells three patterns were noted: Trk-positive - pc-Jun/pJNK-positive cells, Trk-positive -
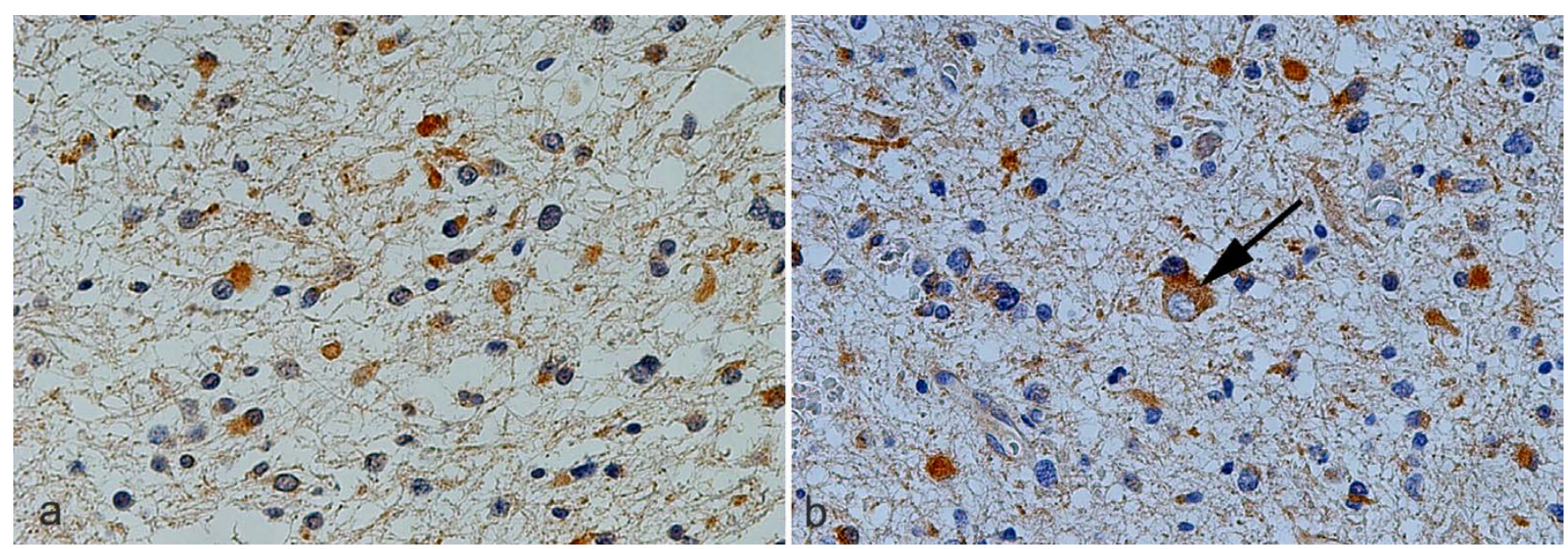

Figure I

TrkB (a) and TrkC (b) immunoexpression in homologous fields of immediately adjacent sections of diffuse fibrillary astrocytoma (grade II). Note the cellular distribution of TrkC receptor in a morphologically indistinguishable cell (arrow) from the nearby cells, $\times 400$. 


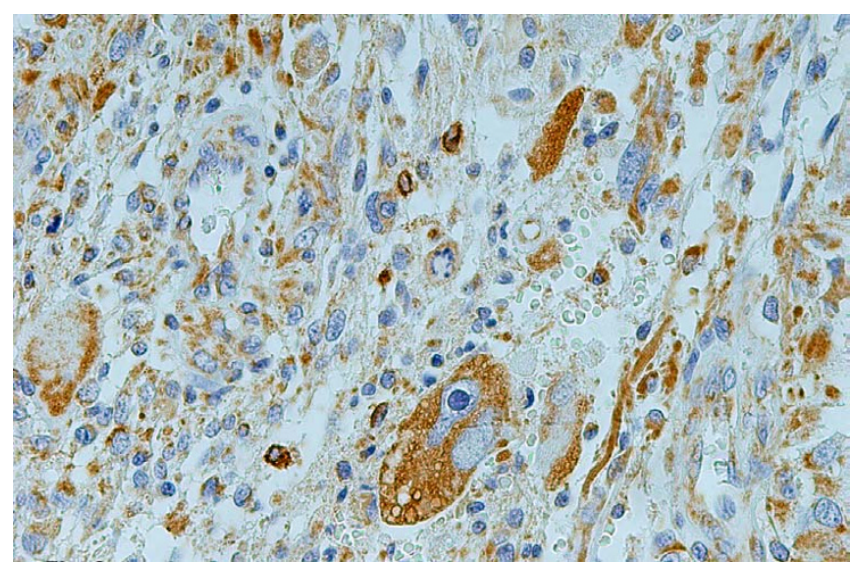

Figure 2

Strong TrkA granular cytoplasmic immunostaining in giant cells of glioblastoma multiforme (grade IV), $\times 400$.

pc-Jun/pJNK-negative cells and Trk-negative - pc-Jun/ pJNK-positive cells (Figure 3, 4). Interestingly, TrkB expression was significantly correlated with pc-Jun expression (Spearman correlation $=0.60, \mathrm{p}=0.002$ ) and $\mathrm{pJNK}$ expression (Spearman correlation $=0.63$, $\mathrm{p}=0.001$ ). Furthermore, TrkC expression was significantly correlated with pJNK expression (Spearman correlation $=0.62, \mathrm{p}=$ $0.002)$.

Some glioblastomas multiforme (gradeIV) showed a reverse relationship between Trk and pc-Jun/pJNK LIs. In other words, a high LI for Trk expression was associated with a low LI for pc-Jun/pJNK expression in the same tumor and vice versa (Table 1 ). In this subgroup of glioblastomas multiforme (grade IV) a statistically significant negative correlation between LIs for panTrk expression and pc-Jun/pJNK was found (Spearman correlation of panTrk with pc-Jun $=-0.7, \mathrm{p}=0.01$, Spearman correlation of panTrk with pJNK $=-0.7, \mathrm{p}=0.008)$.

\section{Discussion}

There is growing evidence relating neurotrophin receptors expression in pathogenesis of astrocytomas. Wang et al. (1998) have detected TrkA, TrkB and TrkC expression in neoplastic astrocytes but not in neoplastic oligodendrocytes and suggested that Trk expression may be useful for lineage marking but unrelated to any signaling cascade involved in the maintenance of a transformed phenotype [16]. On the other hand, Wadhwa et al. (2003) have found a high TrkA and TrkB expression in low grade astrocytic tumors (grade I and grade II) and a down regulation of both Trk receptors in high grade tumors (grade III and grade IV) and concluded that these receptors may contribute to progression towards malignancy [17]. Recently, Chiaretti et al. (2004) showed that there might be an association between neurotrophin receptors expression and the pathobiology of childhood low-grade astrocytomas (grade I and II) [18].

Recent data support that, in glial cells, neurotrophins, through their Trk receptors, may act as mitogens in response to injury [25] and promote cell growth in glioblastoma cell lines [26]. Thus, the overexpression of Trk receptors (independently of grade) found in astrocytomas in the present study, may indicate an accelerated downstream tumor cell survival signaling pathway and suggests a potential mechanism for malignant transformation even in low grade astrocytomas.

In contrast to gliomas, tumors of neuroepithelial origin such as medulloblastomas [19,20] and neuroblastomas [21] which express Trk receptor have a favorable prognosis. It seems that neurotrophins may activate, through their receptors, distinctly different signaling pathways in cells of different lineages.

Trk receptors are often co-expressed with p75 NTR and in such instances pro-apoptotic responses of p75 NTR e.g. activation of JNK pathway, are, in most cases, suppressed [4]. The absence of p $75^{\mathrm{NTR}}$ neurotrophin receptor in astrocytomas included in this study erases the possibility of apoptosis mediated by binding of pro-neurotrophins (proNGF and/or pro-BDNF) to p75 ${ }^{\mathrm{NTR}}$, even in the presence of survival-promoting Trk receptors [5-8], in these tumors.

However, JNK activation has been reported in human gliomas [11] and a grade-dependent expression of pc-Jun/ pJNK was detected in the present study. It is worth noting that a reverse relationship between Trk and pc-Jun/pJNK LIs was detected in some glioblastomas multiforme (grade IV). It seems that glial cell survival may result from a balance between positive and negative regulators (modulated by activation of selective signaling pathways through tyrosine kinases and cytokines receptors). Previous data demonstrate also that cross talk between neurotrophin/Trk signal transduction axis and JNK pathway play a specific role in glial cell migration [27]. Considering the fact that gliomas are widely infiltrating tumors, future studies would elucidate the significance of the above findings with respect to biological behavior of human astrocytomas.

TrkB receptor expression detected in tumor vessels suggests that these receptors may be an important component of the angiogenic cascade required for the development of astrocytic tumors in view of recent data showing the neurotrophin-dependent proliferation of brain capillary endothelial cells [28].

Finally, tumor cells acquire the ability to activate several pathways in order to survive and neurotrophin/Trk signal 

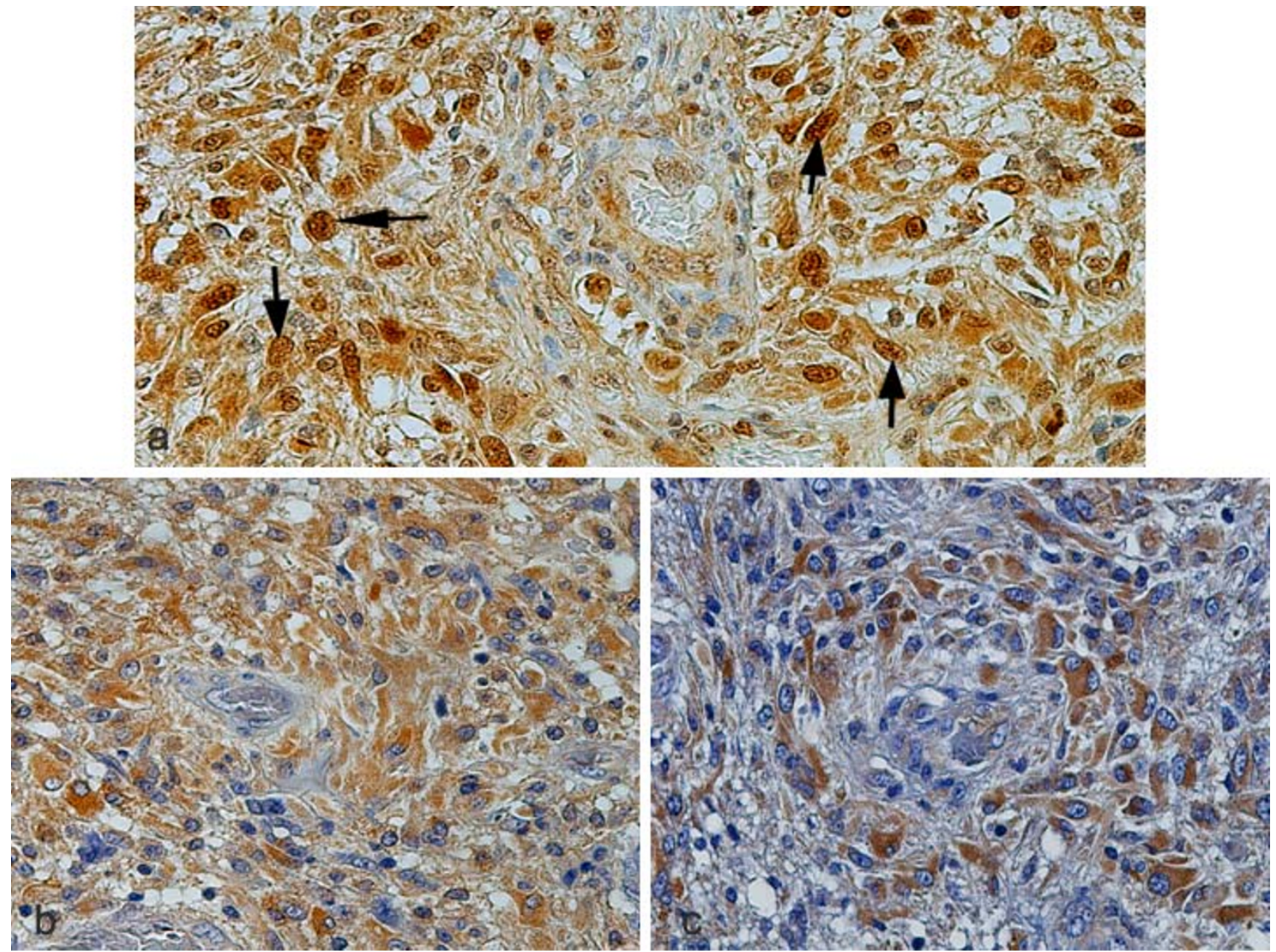

\section{Figure 3}

Serial sections of glioblastoma multiforme (grade IV) depicting strong nuclear (arrows) and cytoplasmic immunostaining of pcJun (a) and strong cytoplasmic immunostaining of neurotrophin receptors TrkB (b) and TrkC (c), $\times 400$.

transduction axis as well as JNK pathway may regulate such survival possibilities. The complexity and cross talk between different signaling cascades may limit the potential therapeutic efficacy of targeting a single molecule. Therefore, it appears necessary to develop an expanded molecular sub-classification of these tumors and to consider combinatorial treatment regimens targeted at different pathways. However, astrocytomas are strikingly heterogeneous tumors in terms of protein profile even within a single tumor which may be a limiting factor in the immunohistochemical evaluation of protein expression levels in these tumors.

\section{Conclusion}

Trk (TrkA, TrkB, TrkC) receptor overexpression may promote tumor cell survival and enhance tumor growth while p75 NTR mediated apoptosis has no functional role in human astrocytomas. Activation of JNK pathway may contribute to progression towards malignancy. Further studies would elucidate the significance of the reverse relationship between Trk LIs and pc-Jun/pJNK LIs. As tumor cells activate several pathways in order to survive, future therapeutic approach may consider combinatorial treatment regimens targeted at different pathways.

\section{Competing interests}

All authors declare that there are no financial or nonfinancial competing interests (political, personal, religious, ideological, academic, intellectual, commercial or any other) in relation to this manuscript.

\section{Authors' contributions}

MA conceived of the study, carried out the design, participated in analysis of immunostaining, performed the sta- 

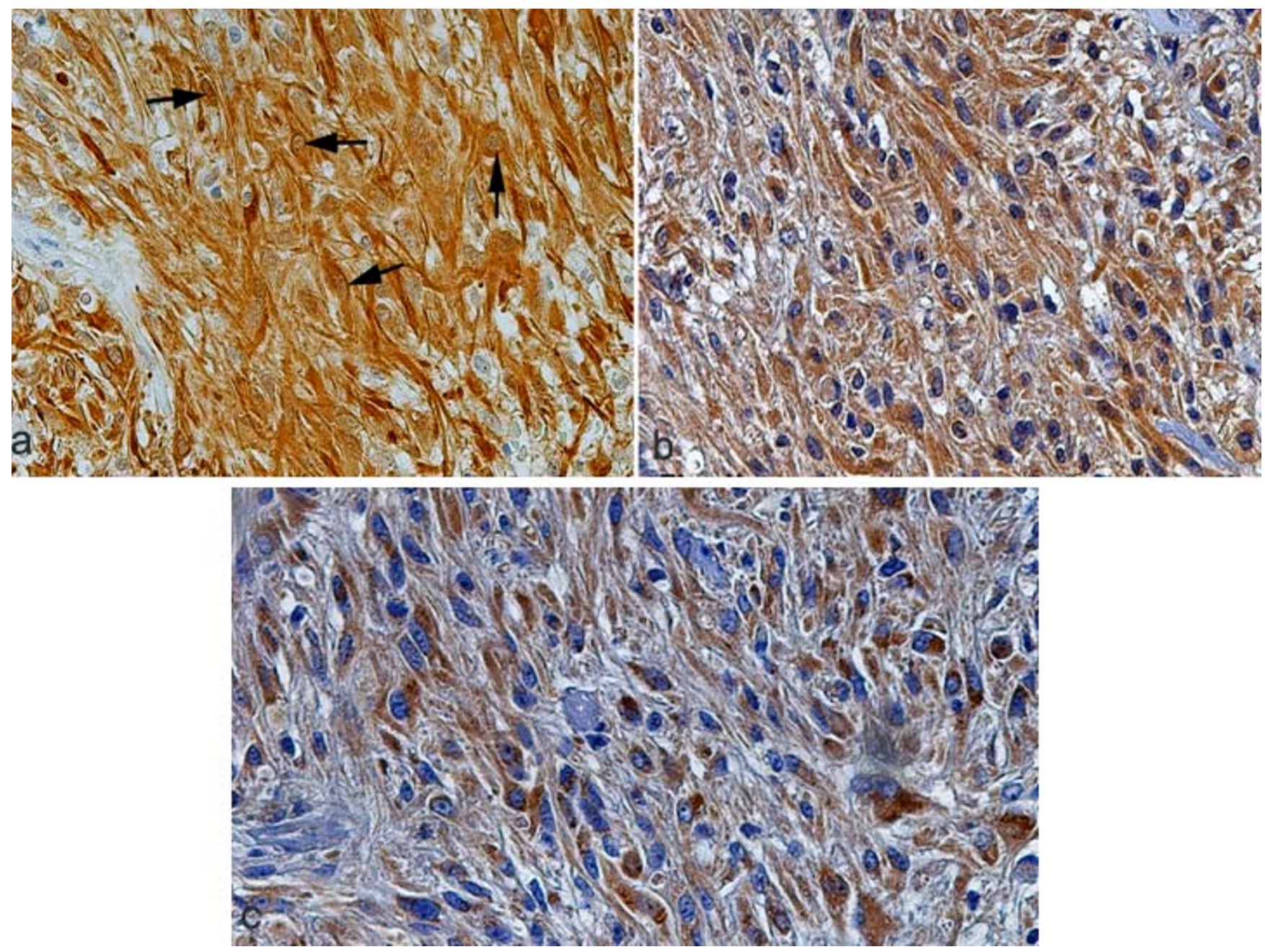

\section{Figure 4}

Grade IV tumor (glioblastoma multiforme) exhibiting strong nuclear (arrows) and cytoplasmic immunostaining of pJNK and strong cytoplasmic immunostaining of TrkB (b) and TrkC (c) neurotrophin receptors, $\times 400$.

tistical analysis, and wrote the manuscript; MK carried out the immunostaining, participated in analysis of immunostaining, and drafted the manuscript. GG supplied clinical data and reviewed the manuscript; TM supplied clinical data and reviewed the manuscript; JV carried out the pathological staging and helped in its design and critical review of the manuscript. All authors have read and approved the final manuscript.

\section{Acknowledgements}

The authors would like to thank the Department of Pathology, School of Medicine, University of Patras for providing tumor samples.

\section{References}

I. Chao MV: Neurotrophins and their receptors: a convergence point for many signaling pathways. Nature Rev Neurosci 2003, 4:299-307.
2. Serafeim A, Gordon J: The immune system gets nervous. Cur Opin Pharmacol 200I, 1:398-403.

3. Kaplan DR, Miller FD: Neurotrophin signal transduction in the nervous system. Cur Opin Neurobiol 2000, 10:38I-391.

4. Patapoutian A, Reichardt LF: Trk receptors: mediators of neurotrophin action. Cur Opin Neurobiol 200I, I I:272-280.

5. Teng HK, Teng KK, Lee R, Wright S, Tevar S, Almeida RD, Kermani $P$, Torkin R, Chen ZY, Lee FS, Kraemer RT, Nykjaer A, Hempstead $B L:$ ProBDNF induces neuronal apoptosis via activation of a receptor complex of p75NTR and sortilin. J Neurosci 2005, 25:5455-5463.

6. Hempstead BL: Dissecting the diverse actions of pro- and mature neurotrophins. Curr Alzheimer Res 2006, 3:19-24.

7. Volosin M, Song W, Almeida RD, Kaplan DR, Hempstead BL, Friedman WJ: Interaction of survival and death signaling in basal forebrain neurons: roles of neurotrophins and proneurotrophins. I Neurosci 2006, 26:7756-7766.

8. Domeniconi M, Hempstead BL, Chao MV: Pro-NGF secreted by astrocytes promotes motor neuron cell death. Mol Cell Neurosci 2007, 34:27I-279.

9. Davis RJ: Signal transduction by the JNK group of MAP kinases. Cell 2000, 103:239-252. 
10. Brecht S, Kirchhof R, Chromik A, Willesen M, Nikolaus T, Raivich G, Wessig J, Waetzig V, Goetz M, Claussen M, Pearce D, Kuan C, Vaudano E, Behrens A, Agner E, Flavell RA, Davis RJ, Herdegent T: Specific pathophysiological functions of JNK isoforms in the brain. Eur J Neurosci 2005, 21:363-377.

II. Tsuiki H, Tnani M, Okamoto I, Kenyon LC, Emlet DR, HolgadoMadruga M, Lanham IS, Joynes CJ, Vo KT, Wong AJ: Constitutively active forms of c-Jun $\mathrm{NH}$-terminal kinase are expressed in primary glial tumors. Cancer Res 2003, 63:250-255.

12. Kleihues P, Cavenee WK: Pathology and Genetics of Tumours of the Nervous System Lyon: IARC Press; 2000.

13. Ichimura K, Ohgaki H, Kleihues P, Collins VP: Molecular pathogenesis of astrocytic tumours. J Neurooncol 2004, 70:137-160.

14. Nakagawara A: Trk receptor tyrosine kinases: a bridge between cancer and neural development. Cancer Let 200I, 169:107-|14.

15. Tajima Y, Molina RP Jr, Rorke LB, Kaplan DR, Radeke M, Feinstein SC, Lee VM-Y, Trojanowski JQ: Neurotrophins and neuronal versus glial differentiation in medulloblastomas and other pediatric brain tumors. Acta Neuropathol 1998, 95:325-332.

16. Wang Y, Hagel C, Hamel W, Müller S, Kluwe L, Westphal M: TrkA, $B$, and $C$ are commonly expressed in human astrocytes and astrocytic gliomas but not by human oligodendrocytes and oligodendrogliomas. Acta Neuropathol 1998, 96:357-364.

17. Wadhwa S, Nag TC, Jindal A, Kushwaha R, Mahapatra AK, Sarkar C: Expression of the neurotrophin receptors TrkA and TrkB in adult human astrocytoma and glioblastoma. J Biosci 2003, 28: $18 \mid-188$.

18. Chiaretti A, Aloe L, Antonelli A, Ruggiero A, Piastra M, Riccardi R, Tamburrini G, Di Rocco C: Neurotrophin factor expression in childhood low-grade astrocytomas and ependymomas. Childs Nerv Syst 2004, 20:412-419.

19. Muragaki Y, Chou TT, Kaplan DR, Trojanowski JQ, Lee VM-Y: Nerve growth factor induces apoptosis in human medulloblastoma cell lines that express TrkA receptors. J Neurosci 1997, I7:530-542.

20. Grotzer MA, Janss AJ, Fung K, Biegel JA, Sutton LN, Rorke LB, Zhao $\mathrm{H}$, Cnaan A, Phillips PC, Lee VM, Trojanowski JQ: TrkC expression predicts good clinical outcome in primitive neuroectodermal brain tumors. J Clin Oncol 2000, 18:1027-1035.

21. Brodeur GM: Neuroblastoma: biological insights into a clinical enigma. Nat Rev Cancer 2003, 3:203-216.

22. Rich JN, Bigner DD: Development of novel targeted therapies in the treatment of malignant glioma. Nat Rev Drug Discov 2004, 3:430-446.

23. Rich JN, Reardon DA, Peery T, Dowell JM, Quinn JA, Penne KL, Wikstrand CJ, Van Duyn LB, Dancey JE, McLendon RE, Kao JC, Stenze TT, Rasheed A, Tourt-Uhlig SE, Herndon JE, Vredenburgh J], Sampson $\mathrm{JH}$, Friedman AH, Bigner DD, Friedman HS: Phase II trial of gefitinib in recurrent glioblastoma. I Clin Oncol 2004, 22: I33-142.

24. Kondyli M, Varakis J, Assimakopoulou M: p75NTR and Trk neurotrophin receptors expression in Enteric Nervous System of human adults. Anat Sci Int 2005, 80:223-228.

25. Ebadi M, Bashir RM, Heidrick ML, Hamada FM, Refaey HE, Hamed A, Helal G, Baxi MD, Cerutis DR, Lassi NK: Neurotrophins and their receptors in nerve injury and repair. Neurochem Int 1997, 30:347-374.

26. Singer HS, Hansen B, Martinie D, Karp CL: Mitogenesis in glioblastoma multiforme cell lines: a role for NGF and its TrkA receptors. J Neurooncol 1999, 45: I-8.

27. Yamauchi J, Chan JR, Shooter EM: Neurotrophin 3 activation of TrkC induces Schwann cell migration through the c-Jun $\mathbf{N}$ terminal kinase pathway. Proc Natl Acad Sci 2003, 100: $1442 \mid-14426$

28. Moser KV, Reindl M, Blasig I, Humpel C: Brain capillary endothelial cells proliferate in response to NGF, express NGF receptors and secrete NGF after inflammation. Brain Res 2004, 1017:53-60.

\section{Pre-publication history}

The pre-publication history for this paper can be accessed here: http://www.biomedcentral.com/1471-2407/7/202/pre pub
Publish with Biomed Central and every scientist can read your work free of charge

"BioMed Central will be the most significant development for disseminating the results of biomedical research in our lifetime. "

Sir Paul Nurse, Cancer Research UK

Your research papers will be:

- available free of charge to the entire biomedical community

- peer reviewed and published immediately upon acceptance

- cited in PubMed and archived on PubMed Central

- yours - you keep the copyright
BioMedcentral 